\title{
Uma Análise Acústica das Vogais \\ Orais, Nasais e Nasalizadas no Dialeto de Vitória da Conquista, Bahia
}

\author{
An Acoustic Analysis of the Oral, Nasal and Nasalized Vowels \\ in the Dialect of Vitória da Conquista, Bahia
}

Luiz Carlos da Silva SOUZA*

Vera PACHECO**

Resumo: Partindo do pressuposto de que, no Português do Brasil (PB), existem dois tipos de nasalidade vocálica, uma que é fonológica, representada pela estrutura /VN./, a vogal nasal, e outra fonética, ocasionada pela presença de uma consoante nasal, mas que não gera oposição na língua, a vogal nasalizada, este trabalho tem por objetivo discutir a natureza dessas vogais, comparando-as com as suas contrapartidas orais, a partir da análise acústica dos três primeiros formantes das vogais do triângulo vocálico, $a$, $i$ e $u$, nas posições inicial, medial e final. Os resultados indicam que as vogais /aN/ e /ã/ apresentam comportamento mais delimitado em relação à sua contrapartida oral do que as outras vogais. A diferença entre as nasais e as nasalizadas não é clara, em se tratando de seus formantes orais. É necessário, portanto, investigar outros parâmetros acústicos, como os formantes nasais e os antiformantes, por exemplo, para que se possa traçar o padrão acústico desses sons.

Palavras-chave: Vogais nasais. Formantes. Acústica.

Abstract: From the proposal that in Brazilian Portuguese (BP) there are two types of vocalic nasality, one which is phonological, represented by the

\footnotetext{
* Mestrando em Linguística, na Universidade Estadual do Sudoeste da Bahia (UESB). Bolsista da CAPES. Contato: luizcarlossil@gmail.com.

** Doutorado em Linguística pela Universidade Estadual de Campinas (2006). Professora titular da Universidade Estadual do Sudoeste da Bahia. Contato: vera.pacheco@gmail.com.
} 
structure /VN./, the nasal vowel, and another one that is phonetic, occasioned by the presence of a nasal consonant, but which does not generates opposition in the language, the nasalized vowel, this paper aims to discuss the nature of these vowels, comparing them with their oral counterparts, from the acoustic analysis of their first three formants of the vowels of the vocalic triangle, $a, i$ and $u$, in the initial, medial and final positions. The results indicate that the vowels /aN/ and / $/$ / have behavior more delimited in relation to their oral counterpart than the other vowels. The difference among the nasal and nasalized vowels is not clear, regarding their oral formants. Therefore it is necessary to investigate other acoustic parameters, like the nasal formants and the antiformants, for example, in order to establish the acoustic pattern of theses sounds.

Key-words: Nasal vowels. Formants. Acoustics.

\section{Introdução}

Ao tratar da nasalização vocálica, Sousa (1994) chama a atenção para dois tipos de nasalidade: a nasalidade decorrente da presença de uma consoante nasal, que, pelo efeito de coarticulação, nasaliza a vogal adjacente, e a nasalidade propriamente dita; nesse segundo tipo não existe aparentemente consoante nasal contígua à vogal nasalizada que justifique a nasalidade por coarticulação, por isso o véu se abaixa já desde o início da realização dessa vogal; as vogais geradas por esse processo seriam as vogais nasais.

Câmara Jr. (1970) afirma que não existem, no Português do Brasil doravante $\mathrm{PB}$-, vogais nasais como as descritas acima, uma vez que, nessa língua, segundo o autor, não se pode estabelecer a oposição entre /ã / e /aN/ como ocorre no Francês entre as palavras bon ['bõ] e bonne ['bon], por isso as vogais nasais do PB apresentam natureza bifonêmica, ou seja, são vogais seguidas por um elemento consonântico nasal chamado de arquifonema nasal, como em canta, por exemplo. Nesse sentido, a nasalização ocorreria pela presença da consoante nasal, ou seja, não seria uma nasalidade própria da vogal.

No entanto, costuma-se atribuir no $\mathrm{PB}$ o nome de nasais às vogais que ocorrem em canta, a fim de diferenciá-las do caso de nasalização vocálica que ocorre em cana, por exemplo, no qual a primeira vogal seria chamada de nasalizada. A diferença entre essas vogais está no papel fonológico que 
elas desempenham no sistema do PB: em canta, a consoante nasal nasaliza a vogal precedente e, normalmente, deixa de ser realizada foneticamente, gerando a oposição entre canta e cata; a nasalização da vogal, nesse caso, é importante para a distinção entre ambas as palavras. Por outro lado, não existe oposição entre cana, realizada como [Ëkãna], e cana, realizada como [Èkana]; nesse caso, a nasalização não é categórica e é importante para a distinção entre dialetos no PB.

Em termos articulatórios, tanto as vogais nasais quanto as nasalizadas são produzidas a partir do mesmo mecanismo, isto é, com a passagem simultânea do ar pelas cavidades oral e nasal. Isso implica dizer que são os mesmos sons, mas com status fonológico diferentes.

Com base nisso, questiona-se se em que medida as vogais nasais e as nasalizadas no PB diferenciam-se entre si no que concerne às suas características acústicas. A literatura apresenta poucos estudos acerca das vogais nasalizadas do PB. Na maioria das vezes, são investigadas somente as vogais nasais, sem se levar em consideração que o status das vogais nasalizadas pode oferecer subsídios para o melhor entendimento daquelas. Alguns trabalhos têm acenado para o comportamento particular das vogais nasalizadas, o que justifica a realização de um estudo fonético-fonológico mais consistente a respeito das mesmas.

\section{A Articulação das Vogais Nasais e sua Relação com os seus Aspectos Acústicos}

$\mathrm{Na}$ produção dos sons das línguas naturais, o ar vindo dos pulmões pode ser emitido por duas cavidades: a oral e a nasal. A cavidade oral é aquela que vai da faringe à boca, e a nasal, da faringe às fossas nasais.

A maioria dos sons, como as consoantes e as vogais orais, é gerada pela passagem do ar somente pela cavidade oral; para isso, o véu palatino encontra-se levantado, com a ajuda de alguns músculos, dentre eles, o Levantador do Palato, impedindo, assim, a passagem do ar pelas fossas nasais.

As consoantes nasais são produzidas com uma obstrução na cavidade oral e passagem do ar pela cavidade nasal, a qual é possibilitada pelo abaixamento do véu palatino, com o auxílio do músculo chamado de Palatoglosso, responsável também por fazer com que a língua se eleve. 
As vogais nasais, por sua vez, são realizadas devido à passagem do ar tanto pela cavidade oral quanto pela nasal, como consequência do abaixamento do véu palatino; como resultado, o tubo da cavidade oral é acoplado ao tubo da cavidade nasal.

Lovatto et al. (2007) confirmam o abaixamento do véu palatino durante a produção das vogais nasais. De acordo com sua pesquisa, a antecipação do movimento velar antes da vogal nasal é sistemática, porém difere a depender da posição nas palavras. No entanto, a partir de outros dados, que mostram a posição do véu palatino durante a produção de consoantes e vogais nasais, os autores chamam a atenção para o fato de que o abaixamento antecipatório do véu não é suficiente para explicar a presença das vogais nasais. Sugere-se que a nasalização não é somente um movimento binário de abertura e fechamento do véu. A abertura da cavidade velofaríngea é necessária, mas não é condição eficiente para a produção da vogal nasal. A posição da articulação secundária, como a posição da língua ou dos lábios, parece ser mais importante para contrastar a nasalização entre o Português do Brasil e o Francês.

O acoplamento de tubos durante a produção das vogais nasais tem como consequências acústicas a redução da intensidade dos formantes da vogal, o aparecimento de formantes nasais, com o fim de compensar essa redução, a presença de antirressonâncias (antiformantes ou zeros), que são frequências com baixa intensidade, presentes entre os formantes orais, cuja localização varia de vogal para vogal, atenuação geral da amplitude e na frequência dos formantes orais, aumento da largura de banda dos formantes, existência de um formante nasal em torno de $250 \mathrm{~Hz}$ e pela mudança na posição relativa de frequência de formantes.

\section{Sobre a Duração das Vogais Nasais e Nasalizadas}

Com o desenvolvimento da fonética experimental, muitos trabalhos têm sido realizados com o fim de colaborar para uma melhor compreensão acerca das vogais nasais. Nessa perspectiva, Moraes e Wetzels (1992) analisaram a duração dos segmentos vocálicos nasais, aqueles que podem ser chamados de fonemas, como em canta, e nasalizados, aqueles que adquirem a nasalidade apenas por influência de uma consoante nasal da sílaba seguinte, mas não estabelecem contraste fonológico, como em cama, por exemplo. Com isso, objetivaram verificar se as vogais nasais são de natureza mono 
(V) ou bifonêmica $(\mathrm{V}+\mathrm{N})$. Os autores encontraram que as vogais nasais são mais longas que as orais, o que poderia ratificar que a vogal nasal tivesse natureza bifonêmica. Porém foi verificado ainda que esse alongamento só acontece quando essas vogais precedem uma consoante oclusiva; diante das fricativas, o que ocorre é um encurtamento dessas vogais.

Medeiros (2007) faz uma ressalva a respeito do termo "bifonêmico", alegando que este alude ao conceito de dois fonemas perfeitamente segmentáveis, quais sejam a vogal e a consoante. A autora sugere, então, o termo bifásico. No entanto, a proposta de mudança de nomenclatura não deve, segundo a autora, "minimizar o insight mattosiano" (MEDEIROS, 2007, p. 167). Para ela, “a hipótese VN de Mattoso contemplaria a variabilidade da produção da vogal nasal, uma vez que $V$ representaria a qualidade vocálica e $\mathrm{N}$ abrangeria a porção nasal acrescida ou não do murmúrio nasal" (MEDEIROS, 2007, p. 167).

Pacheco (2004) buscou analisar a duração das vogais travadas não só pela consoante /N/, mas também pelas consoantes /R/ e /S/, em palavras com a estrutura CVC.CV, com oclusiva na segunda sílaba. Os resultados indicaram que a soma da duração das vogais com a duração de qualquer uma dessas consoantes em coda silábico é maior que o valor da vogal em sílaba aberta.

Souza e Pacheco (2007) analisaram as vogais nasais e orais em palavras monossílabas e observaram que as vogais nasais apresentaram valor duracional igual à soma da duração das vogais orais em sílaba fechada com a duração das consoantes de coda / R/ e /S/, ou seja, $\mathrm{VN}=\mathrm{VC}^{1}$, evidências para a natureza bifonêmica das vogais nasais. Porém, verificaram para as vogais nasais um comportamento duracional igual ao das vogais orais em sílaba aberta $(\mathrm{VN}=\mathrm{V})$, valores que podem ser utilizados para confirmar a hipótese de que elas sejam monofonêmicas. Na comparação entre vogais nasais e nasalizadas, assim como foi constatado por Moraes e Wetzels (1992), Souza e Pacheco (2007) encontraram que as vogais nasais apresentam maior duração. Esses dados dão uma maior evidência de que as vogais "nasais" caracterizam-se por serem uma vogal travada por uma consoante nasal, da mesma forma que o são pelas consoantes /R/ e /S/.

${ }^{1} \mathrm{C}$ representa as consoantes / R/ e /S/. 
Também Campos (2009), analisando a duração dos segmentos vocálicos orais, nasais e nasalizados mostra que há uma maior duração da vogal nasal em relação à sua correspondente oral e nasalizada independente da presença do murmúrio nasal, sobre o qual será discutido mais adiante. No entanto, a maior duração está condicionada também à qualidade vocálica, ao ponto e ao modo de articulação da consoante seguinte. A presença e a duração do murmúrio nasal, por sua vez, não dependem da qualidade vocálica nem do ponto de articulação da consoante subsequente; no entanto, a presença do murmúrio nasal está condicionada pelo modo de articulação da consoante seguinte. A autora aponta que o murmúrio nasal esteve presente somente diante de consoantes plosivas. Os resultados estão de acordo com o que se encontra nos estudos a respeito da duração das vogais nasais, apontando para essas uma maior duração em relação às suas correlatas orais e nasalizadas.

\section{As Frequências Formânticas das Vogais Nasais}

Cagliari (1977), em sua investigação acústica, analisou sete vogais orais e duas reduzidas, comparando-as às suas correspondentes nasais. Nos seus dados, Cagliari (1977) encontrou uma diferença de $120 \mathrm{~Hz}$ entre o $\mathrm{F}_{1}$ de [ã] e o $F_{1}$ de sua oral correspondente [a], sendo o valor desta maior que o daquela, e um valor de $\mathrm{F}_{2}$ para [i] mais alto que o do $\mathrm{F}_{2}$ de [i], com uma diferença de $410 \mathrm{~Hz}$. Por outro lado, a vogal nasal baixa é a que apresenta $\mathrm{F}_{1}$ sempre menor que o da sua oral correspondente, indicação da elevação da mandíbula, o que não ocorre com as vogais altas das duas extremidades do triângulo vocálico.

$\mathrm{Na}$ investigação de Sousa (1994), as diferenças entre as médias das vogais orais e das nasais em relação ao $\mathrm{F}_{1}$ são: $738 \mathrm{~Hz}$ para [a] e 630 para [ã]; $291 \mathrm{~Hz}$ para [i] e $279 \mathrm{~Hz}$ para [i] ; $299 \mathrm{~Hz}$ para [u] e $310 \mathrm{~Hz}$ para [i]. Para as vogais [ĩ] e [i], houve, respectivamente, aumento de $\mathrm{F}_{2}$ e $\mathrm{F}_{3}$ em relação a [i] e [u]. A autora destaca ainda a existência e o papel do murmúrio nasal como fase característica da vogal nasal, e que não existe independente dela, assim como acontece com a fase oral.

Medeiros (2007) detecta no espectro da vogal [ĩ] a presença de um formante nasal por volta de $800 \mathrm{~Hz}$, outro cerca de $1400 \mathrm{~Hz}$ e o deslocamento de $\mathrm{F}_{2}$ para $2400 \mathrm{~Hz}$, que demonstra a elevação desse formante em relação ao $\mathrm{F}_{2}$ da vogal oral [i]. Para as vogais baixas nasal e oral, na 
porção medial, o $F_{2}$ encontra-se destacado de $F_{1}$ por um vale na faixa de 700 a $1300 \mathrm{~Hz}$. Para as vogais [i] e [u], na porção medial, as diferenças não são tão grandes, mas se percebe o destacamento de um pico de cerca de $600 \mathrm{~Hz}$ na vogal nasal e grande perda de energia nos picos próximos de 940 $\mathrm{Hz}$, valor correspondente ao $\mathrm{F}_{2}$ da vogal oral.

A fim de apontar a relação entre a diferença de graus de abertura do véu palatino nas vogais nasais e as suas frequências formânticas, Barbosa et al. (2010) investigam as frequências de $\mathrm{F}_{1}, \mathrm{~F}_{2}, \mathrm{~F}_{3}$, formante nasal (Fn) e antiformante (Zero) para as vogais [a] e [ã] para diferentes aberturas feitas no bulbo de réplicas da prótese de palato de uma paciente com disfunção velofaríngea, partindo do pressuposto de que introduzir perfurações experimentais no bulbo faríngeo resulta em fala hipernasal, uma vez que a paciente, ao usar da prótese de palato obturadora para a correção da disfunção velofaríngea (DVF), apresentou fala com ressonância julgada normal em avaliações fonoaudiológicas. Sendo assim, os autores partem da hipótese de que diferentes aberturas geram como consequência diferentes medidas espectrais. Os resultados mostraram que as frequências de $\mathrm{F}_{1}, \mathrm{~F}_{2} \mathrm{e}$ $\mathrm{F}_{3}$ para a vogal oral [a] estiveram entre $655 \mathrm{HZ}$ e $764 \mathrm{~Hz}$ para $\mathrm{F}_{1}$; entre 1339 $\mathrm{Hz}$ e $1571 \mathrm{~Hz}$ para $\mathrm{F}_{2}$; e entre $2095 \mathrm{~Hz}$ e $2627 \mathrm{~Hz}$ para $\mathrm{F}_{3}$.

Os resultados encontrados por Barbosa et al. (2010) mostram que as frequências dos formantes foram menores quando havia abertura velofaríngea. Os valores médios de $\mathrm{F}_{1}, \mathrm{~F}_{2}, \mathrm{~F}_{3}$, em Hertz, da vogal [ã], em "panto e manto" estiveram entre $363 \mathrm{~Hz}$ e $487 \mathrm{~Hz}$ para $\mathrm{F}_{1}$; entre $1167 \mathrm{~Hz}$ e $1371 \mathrm{~Hz}$ para $\mathrm{F}_{2}$; e para $\mathrm{F}_{3}$ entre $2073 \mathrm{~Hz}$ e $2296 \mathrm{~Hz}$. As médias das frequências de formantes orais para a vogal nasal [ã], em panto e manto foram bem menores que as da vogal [a], em pato e mato. Nas condições de abertura de $20 \mathrm{~mm}^{2}$ e de $30 \mathrm{~mm}^{2}$ na prótese, a vogal [a] se comportou de maneira semelhante a todas as condições da vogal nasal [ã] em relação ao $\mathrm{F}_{2}$, demonstração do efeito da nasalidade importante no final do segundo formante. Quanto à análise do $\mathrm{F}_{3}$, não foram observadas informações relevantes para a nasalidade, uma vez que esse formante é mais afetado pelo contexto consonantal, que, nesse estudo, foi controlado.

Pela análise dos dados de Barbosa et al. (2010), não houve diminuição gradual dos formantes de acordo com o aumento da abertura velofaríngea. Quanto à avaliação perceptivo-auditiva, a presença das antirressonâncias se mostrou essencial para a identificação das vogais nasais pelos juízes fonoaudiólogos. Com isso, os autores confirmaram haver relação entre o tamanho da abertura velofaríngea e as medidas espectrais. 
A investigação nos trabalhos supracitados leva em conta apenas as características acústicas das vogais nasais em relação às suas correspondentes vogais orais. O presente trabalho propõe uma investigação acústica que considere não só os valores formânticos das vogais orais em comparação aos das vogais nasais, como também busca compará-los com os das vogais nasalizadas, aquelas que não apresentam status fonológico, uma vez que não são responsáveis por diferenciar vocábulos no Português do Brasil, com vistas a verificar se estas apresentam comportamento acústico diferente em relação àquelas, como se comportam diferentemente no tocante à duração, de acordo a constatação de Moraes e Wetzels (1992) e Souza e Pacheco (2007), por exemplo.

Com isso, espera-se colaborar para o enriquecimento dos trabalhos sobre o padrão acústico das vogais nasais e fornecer, então, dados concretos para a discussão sobre a natureza das vogais nasais no âmbito da Fonética e consequente auxílio à compreensão dessas no campo da Fonologia.

\section{Material e Métodos}

\subsection{Corpus}

Compôs-se um corpus com palavras dissílabas formadas pela estrutura CVC.CV e CV.CV, nas quais as vogais /a/, /i/ e /u/ ocupam a posição de núcleo silábico; foram escolhidas essas vogais por elas comporem o triângulo vocálico e obedecerem a um padrão formântico de consenso entre os pesquisadores que corresponde às características típicas de vogais que apresentam o máximo e o mínimo de abertura vocálica e de movimento de recuo e de avanço, de abaixamento e levantamento da língua. A posição das consoantes em onset seguido de sílaba travada, neste caso pelo arquifonema nasal /N/, é ocupada por oclusivas e fricativas, enquanto que as consoantes nasais $/ \mathrm{m} / \mathrm{e} / \mathrm{n} /$ ocupam a posição de onset seguido por sílaba aberta. Com isso, a partir de palavras como "cata", "canta" e "cana", por exemplo, pôde-se verificar a diferença entre os formantes das vogais nasais, nasalizadas e orais. Procurou-se fazer com que as vogais orais e nasais de cada trio antecedessem, nas palavras em que estavam inseridas, a mesma consoante. As palavras foram inseridas na frase-veículo "Digo baixinho". A inserção das palavras numa frase-veículo justifica-se pela necessidade de se homogeneizar o contexto para todas elas e manter, na medida do possível, 
o controle de aspectos prosódicos, como entonação, por exemplo, evitandose, assim, interferências outras sobre a realização dos sons em questão.

As palavras componentes do corpus utilizado foram as seguintes:

- Canta x Cata x Cana

- Campa x Capa x Cama

- Pinta x Pita x Pino

- Quincas x Quica x Quimo

- Cunca x Cuca x Cume

- Panca x Paca x Pano

- Pinda x Pida x Pina

- Pimpa x Pipa x Pina

- Tunda x Tudo x Tuna

- Panga x Paga x Pana

- Cansa x Caça x Cano

- Finfa x FIFA x Fina

- Lunfa x Lufa x Lume

- Pança x Passa x Pana

- Dunfa x Ducha x Duna

- Lincha $x$ Lixa x Lina

\subsection{Gravação do corpus}

As gravações foram efetuadas em cabine acusticamente tratada no Laboratório de Pesquisa e Estudos em Fonética e Fonologia (LAPEFF), da Universidade Estadual do Sudoeste da Bahia (UESB), através do programa Audacity a uma taxa de amostragem de $44100 \mathrm{~Hz}$ (Mono), em 16 bits. As frases foram impressas individualmente em papéis brancos e apresentadas de forma aleatória com um intervalo de tempo indeterminado entre uma frase e outra, aos informantes desta pesquisa, em sessões individualizadas. Cada frase foi gravada quatro vezes aleatoriamente em taxa de elocução normal. Participaram da gravação 3 (três) informantes, sem problemas de fala, sendo 2 (dois) do sexo masculino e 1 (um) do sexo feminino, todos universitários, com idade entre 18 e 30 anos, baianos, naturais de Vitória da Conquista e região. 
4.3 Obtenção dos valores dos três primeiros formantes $\left(F_{1}, F_{2}\right.$ e $\left.F_{3}\right)$, dos formantes nasais e dos antiformantes

Os valores dos três primeiros formantes $\mathbf{F}_{1}, \mathbf{F}_{2} \mathbf{e} \mathbf{F}_{\mathbf{3}}$ foram obtidos a partir do programa Praat, considerando-os nas porções inicial (P1), medial (P2) e estacionária (P3) das vogais investigadas, como podem ser vistos nas figuras abaixo:

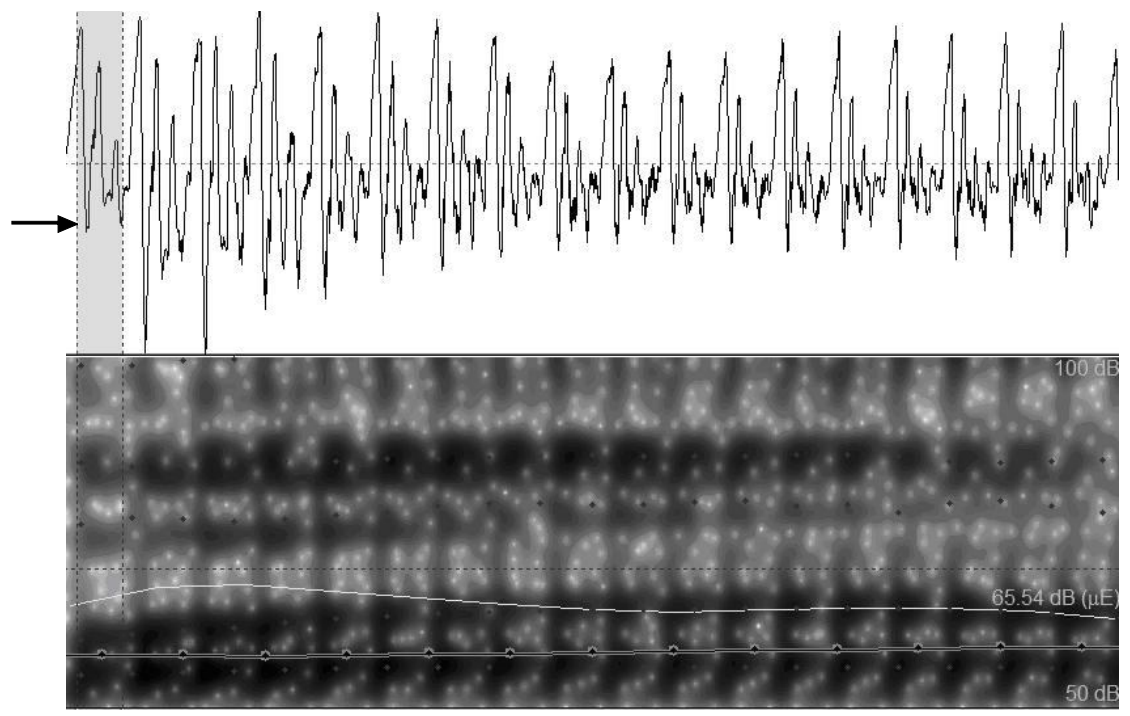

Fonte: elaboração própria

Figura 1 - Estado inicial (P1) da vogal [a] 


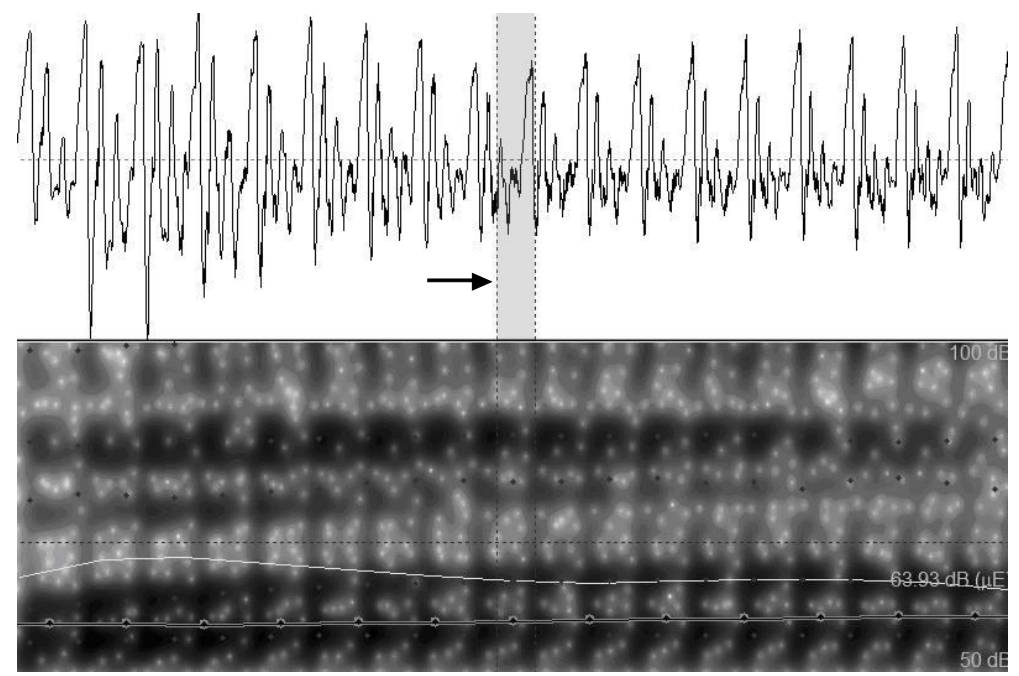

Fonte: elaboração própria

Figura 2 - Estado medial (P3) da vogal [a]

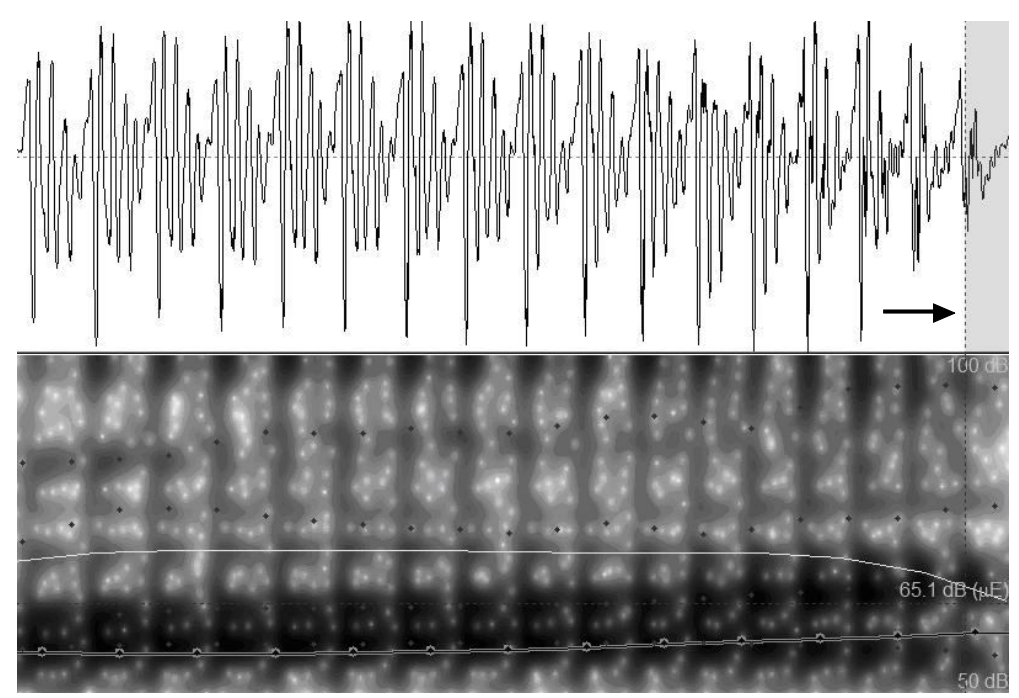

Fonte: elaboração própria

Figura 3 - Estado final (P3) da vogal [a] 
Os valores das frequências formânticas tanto das vogais orais quanto das nasais e das nasalizadas foram extraídos pela ferramenta Formant-Formant listing do Praat. Em seguida, os valores dos formantes nasais e dos antiformantes foram localizados a partir da análise de FFT, obtido através do comando Spectrum-View Spectral Slice do mesmo programa. A partir da imagem de FFT, identificaram-se os formantes 1, 2 e 3 e, em seguida, entre eles, procurou-se localizar os picos e os vales, que indicavam, respectivamente, a presença de formantes nasais (Pólos) e de antiformantes (Zeros). Abaixo, seguem imagens de FFT de um ponto da vogal /aN/ e da vogal /iN/, com os seus respectivos formantes orais, nasais e antiformantes. As setas horizontais indicam os formantes nasais, e as verticais, os antiformantes.

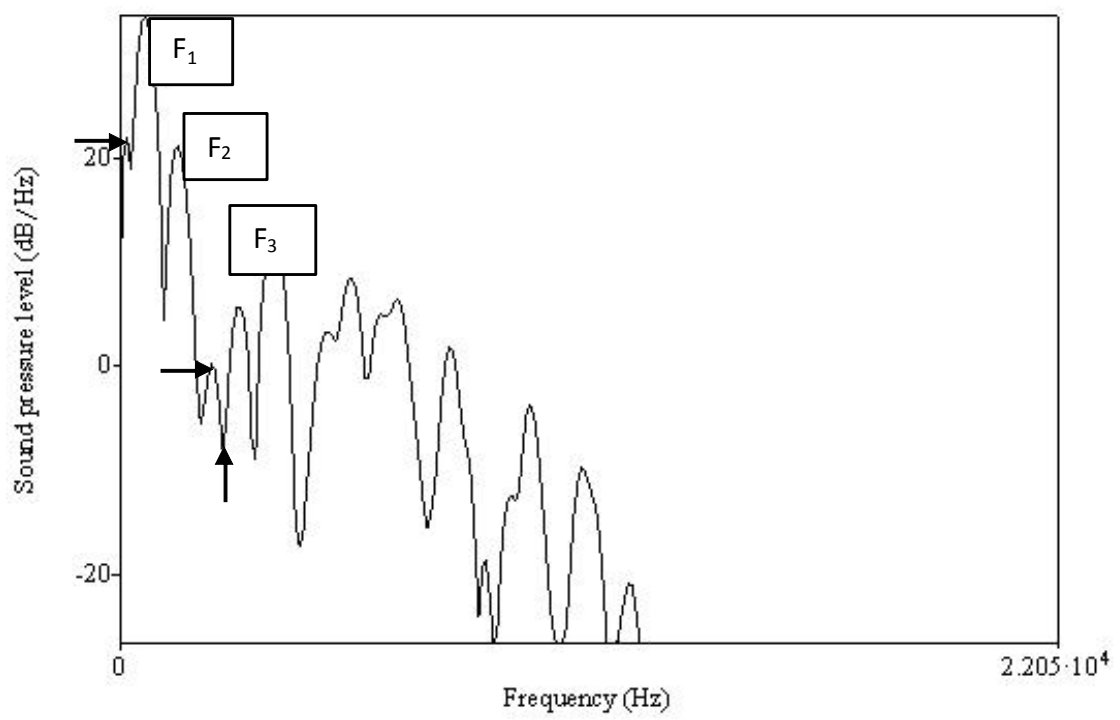

Fonte: elaboração própria

Figura 4 - Análise de FFT da vogal /aN/ 


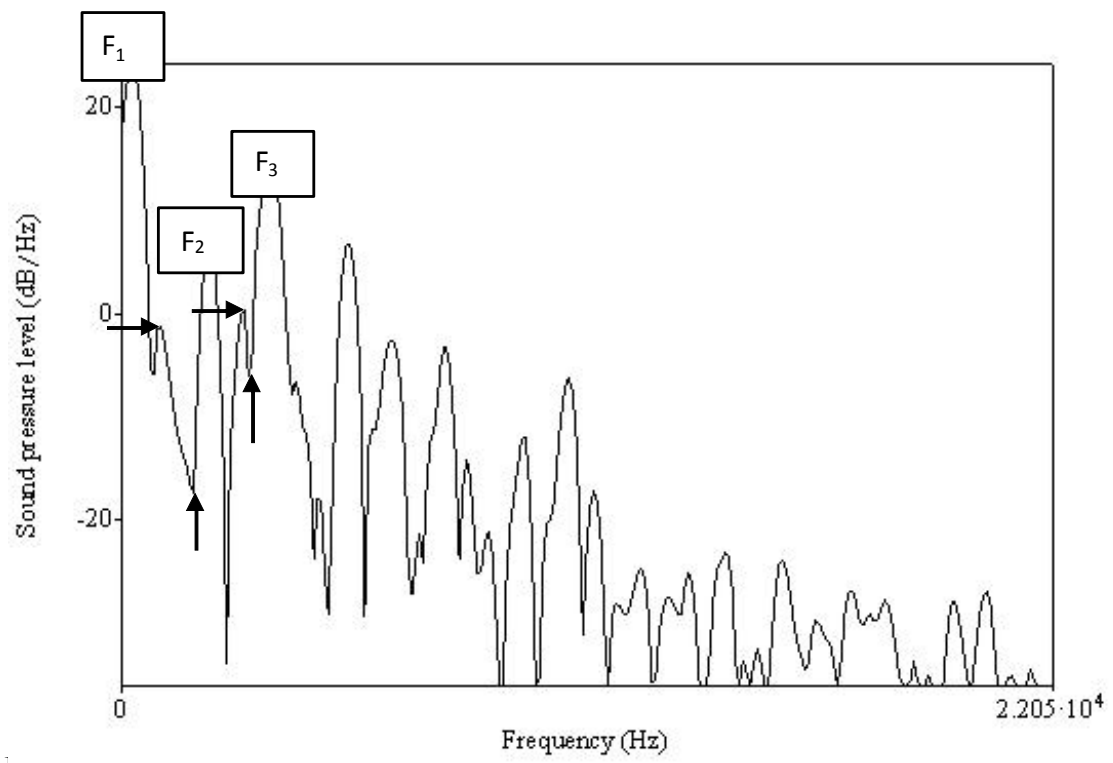

Honte: elaboraçao propria

Figura 5 - Análise de FF'T da vogal /iN/

\subsection{Análise dos dados}

Os dados de cada informante foram submetidos ao teste não paramétrico Kruskall Wallis, para certificar se os valores para cada formante apresentavam diferenças significativas entre si nas porções inicial, medial e final de cada vogal. Em seguida, foram comparados os valores desses formantes, em cada porção, das vogais orais, nasais e nasalizadas. Os formantes das vogais não foram analisados considerando-se o tipo de consoantes que as seguiam. A qualidade da consoante só foi levada em conta para a análise da duração; neste caso, procurou-se analisar a duração dos segmentos vocálicos a partir dos grupos daqueles precedidos por oclusivas e dos precedidos por fricativas. Os valores foram considerados diferentes para $\mathrm{p}<0.05$. 


\section{Resultados e Discussão}

5.1 Comparação entre os valores de $F_{1}, F_{2}$ e $F_{3}$ das vogais orais /a/, /i/ e /u/ e suas correlatas nasais e nasalizadas na posição inicial (P1)

A vogal / a/ tende a apresentar médias de $\mathrm{F}_{1}$ em torno de $700 \mathrm{~Hz}$ para o sexo masculino e de $800 \mathrm{~Hz}$ para o sexo feminino; esse valor baseia-se nas realizações de um falante do sexo masculino com um tubo de tamanho cuja média é de $17,5 \mathrm{~cm}$. Os falantes do sexo feminino apresentam valores $20 \%$ maiores, devido ao tamanho de seu tubo, que costuma ser $15 \%$ menor do que o do homem, o que implica dizer que, quanto menor o tubo, menores frequências, de acordo com Pickett (1999). As vogais baixas apresentam valores de $\mathrm{F}_{1}$ altos em relação às outras vogais, isso porque a língua na produção desses sons encontra-se abaixada e mais recuada se comparada à sua posição quando da produção de um /i/, por exemplo. No caso da vogal /a/, a constrição na faringe faz com que seus valores de $\mathrm{F}_{1}$ sejam os mais altos. No entanto, quando são introduzidos formantes nasais no momento da emissão de vogais nasais, o $F_{1}$ dessa vogal sofre abaixamento, ficando em torno de $500 \mathrm{~Hz}$, conforme apontam categoricamente os dados da tabela abaixo. Em relação aos valores de $\mathrm{F}_{2}$, há dados que apontam para maiores valores de $\mathrm{F}_{2}$ para /aN/ e outros para uma igualdade entre os valores de $\mathrm{F}_{2}$ para $/ \mathrm{a} / \mathrm{e} / \mathrm{aN} /$ ou para $/ \mathrm{aN} / \mathrm{e}$ /ã/. Em relação ao $\mathrm{F}_{3}$, a tendência é de que os valores para /aN/ e /ã / sejam mais altos que para /a/, como mostram o quadro 1 e o gráfico 1 dos dados do IM-3 a seguir: 
Quadro 1 - Valores médios em $\mathrm{Hz}$ de $\mathrm{F}_{1} \mathrm{~F}_{2}$ e $\mathrm{F}_{3}$ em P1 obtidos para a vogal /a/ e suas correlatas nasal e nasalizada e respectivos valores de $\mathrm{p}$

\begin{tabular}{|c|c|c|c|c|c|}
\hline Informantes & Formantes & $/ \mathbf{a} /$ & $/ \mathbf{a N} /$ & $/ \tilde{\mathbf{a}} /$ & $\mathbf{p}$ \\
\hline \multirow{3}{*}{ IM-1 } & $\mathbf{F}_{\mathbf{1}}$ & $615 \mathrm{a}^{(1)}$ & $472 \mathrm{~b}^{(2)}$ & $473 \mathrm{~b}$ & $0.0001(\mathrm{~s})$ \\
\cline { 2 - 6 } & $\mathbf{F}_{\mathbf{2}}$ & $2280 \mathrm{a}$ & $2328 \mathrm{a}$ & $2356 \mathrm{a}$ & 0.0468 \\
\cline { 2 - 6 } & $\mathbf{F}_{3}$ & $2627 \mathrm{a}$ & $2757 \mathrm{~b}$ & $2749 \mathrm{~b}$ & 0.0004 \\
\hline \multirow{4}{*}{ IF-2 } & $\mathbf{F}_{1}$ & $759 \mathrm{a}$ & $624 \mathrm{~b}$ & $626 \mathrm{~b}$ & 0.0001 \\
\cline { 2 - 6 } & $\mathbf{F}_{\mathbf{2}}$ & $1564 \mathrm{a}$ & $1380 \mathrm{~b}$ & $2680 \mathrm{~b}$ & 0.0222 \\
\cline { 2 - 6 } & $\mathbf{F}_{3}$ & $2563 \mathrm{a}$ & $2633 \mathrm{~b}$ & $462 \mathrm{~b}$ & 0.0048 \\
\hline \multirow{3}{*}{$\mathbf{I M - 3}$} & $\mathbf{F}_{\mathbf{1}}$ & $611 \mathrm{a}$ & $459 \mathrm{~b}$ & $1287 \mathrm{bc}$ & 0.0001 \\
\cline { 2 - 6 } & $\mathbf{F}_{\mathbf{2}}$ & $1402 \mathrm{a}$ & $1293 \mathrm{ac}$ & $2516 \mathrm{bc}$ & 0.0256 \\
\cline { 2 - 6 } & $\mathbf{F}_{3}$ & $2304 \mathrm{a}$ & $2497 \mathrm{ac}$ & & 0.0001 \\
\hline
\end{tabular}

Fonte: elaboração própria

Obs.: (1) Letras iguais indicam que não há diferença significativa entre as médias. (2) Letras diferentes indicam que há diferença significativa entre as médias. ${ }^{(3)} \mathrm{s}=$ significativo para valores de $\mathrm{p}$ menores que 0.05 .

Gráfico 1 - Valores médios em $\mathrm{Hz}$ de $\mathrm{F}_{1} \mathrm{~F}_{2}$ e $\mathrm{F}_{3}$ em P1 obtidos para a vogal /a/ e suas correlatas nasal e nasalizada

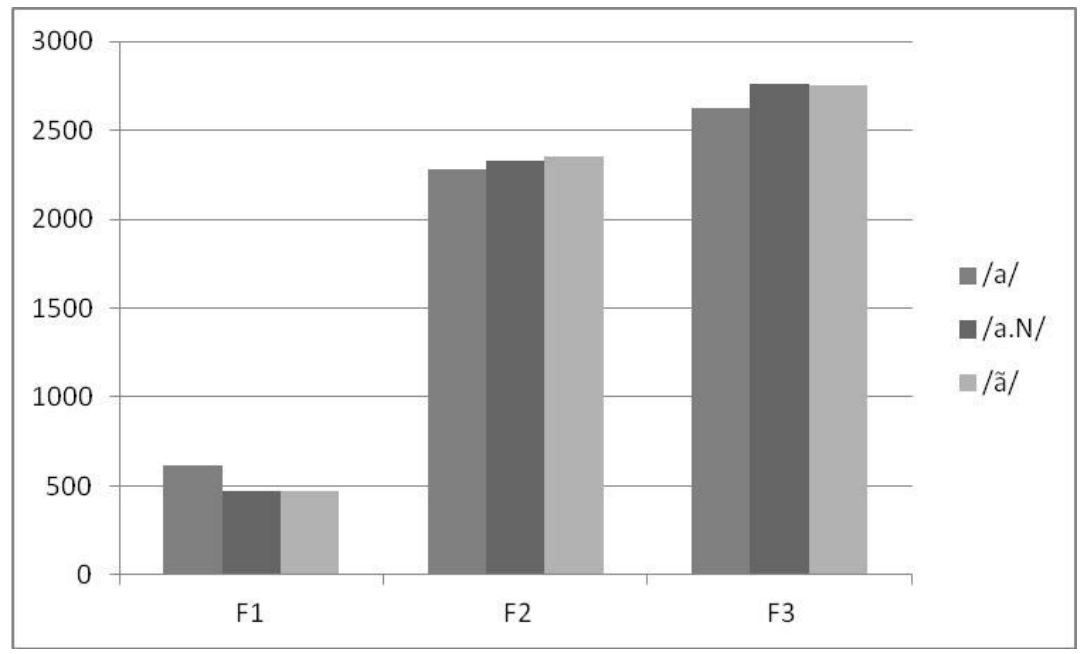

Fonte: elaboração própria 
Em relação aos valores de $\mathrm{F}_{1}, \mathrm{~F}_{2}$ e $\mathrm{F}_{3}$ para as vogais /i/, /iN/ e $\tilde{1} /$, as diferenças foram significativas somente entre os valores de $\mathrm{F}_{2}$ do IM-1, sendo mais alto para /iN/ em relação a /i/, e entre os valores de $\mathrm{F}_{3}$ do IM-3, cujo valor para /iN/ é maior do que para /i/, conforme mostram o quadro 2 e o gráfico 2 que seguem:

Quadro 2 - Valores médios em $\mathrm{Hz}$ de $\mathrm{F}_{1} \mathrm{~F}_{2}$ e $\mathrm{F}_{3}$ em P1 obtidos para a vogal /i/ e suas correlatas nasal e nasalizada e respectivos valores de $\mathrm{p}$

\begin{tabular}{|c|c|c|c|c|c|}
\hline Informantes & Formantes & $/ \mathbf{i} /$ & $/ \mathbf{i N} /$ & $/ \mathbf{i} /$ & $\mathbf{p}$ \\
\hline \multirow{3}{*}{ IM-1 } & $\mathbf{F}_{\mathbf{1}}$ & 296 & 310 & 312 & $0.8058(\mathrm{~ns})^{(3)}$ \\
\cline { 2 - 6 } & $\mathbf{F}_{\mathbf{2}}$ & $2280 \mathrm{a}^{(1)}$ & $2368 \mathrm{~b}^{(2)}$ & $2303 \mathrm{ab}$ & $0.0301(\mathrm{~s})^{(4)}$ \\
\cline { 2 - 6 } & $\mathbf{F}_{3}$ & 3053 & 3107 & 3116 & 0.5515 \\
\hline \multirow{3}{*}{ IF-2 } & $\mathbf{F}_{\mathbf{1}}$ & 401 & 384 & 408 & 0.0838 \\
\cline { 2 - 6 } & $\mathbf{F}_{\mathbf{2}}$ & 2309 & 2385 & 2409 & 0.5798 \\
\cline { 2 - 6 } & $\mathbf{F}_{3}$ & 2889 & 2968 & 2985 & 0.3104 \\
\hline \multirow{3}{*}{$\mathbf{I M - 3}$} & $\mathbf{F}_{\mathbf{1}}$ & 271 & 278 & 284 & 0.6268 \\
\cline { 2 - 6 } & $\mathbf{F}_{\mathbf{2}}$ & 2106 & 2112 & 2061 & 0.7607 \\
\cline { 2 - 6 } & $\mathbf{F}_{3}$ & $3140 \mathrm{a}$ & $3288 \mathrm{~b}$ & $3120 \mathrm{ab}$ & 0.0251 \\
\hline
\end{tabular}

Fonte: elaboração própria

Obs.: (1) Letras iguais indicam que não há diferença significativa entre as médias.

(2) Letras diferentes indicam que há diferença significativa entre as médias.

${ }^{(3)} \mathrm{ns}=$ não significativo para valores de $\mathrm{p}$ maiores que 0.05 .

${ }^{(4)} \mathrm{s}=$ significativo para valores de $\mathrm{p}$ menores que 0.05 . 
Gráfico 2 - Valores médios em $\mathrm{Hz}$ de $\mathrm{F}_{1} \mathrm{~F}_{2}$ e $\mathrm{F}_{3}$ em P1 obtidos para a vogal /i/ e suas correlatas nasal e nasalizada

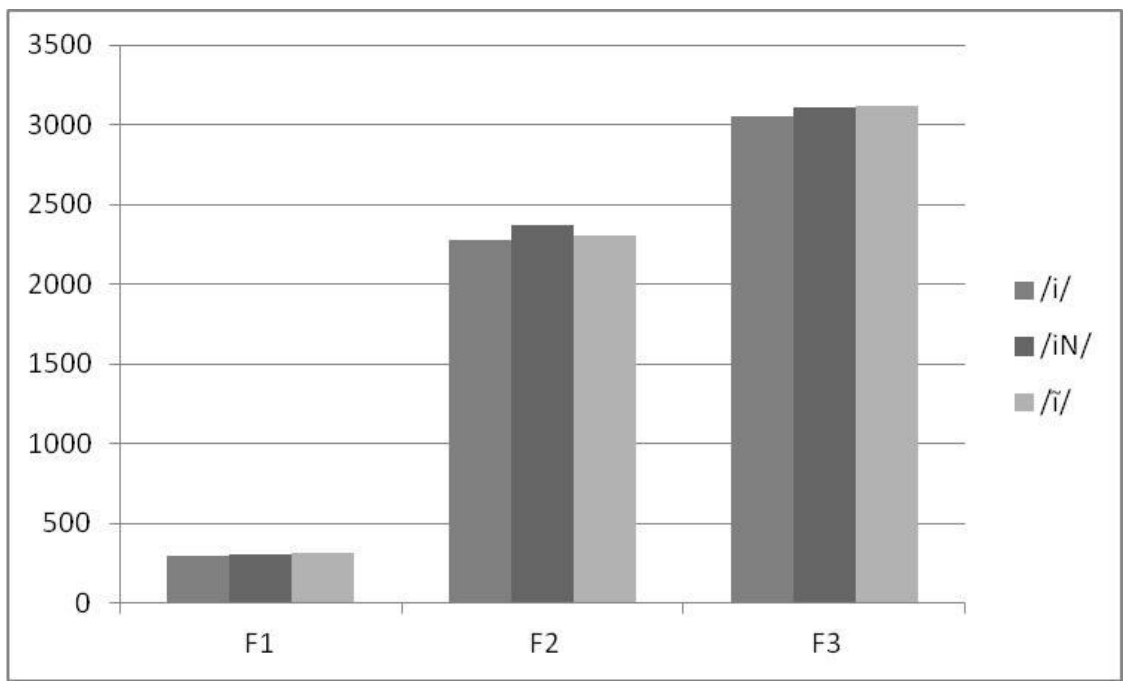

Fonte: elaboração própria

As vogais /u/, /uN/ e / $\tilde{u} /$ não apresentaram diferença significativa entre os seus valores de $\mathrm{F}_{1}, \mathrm{~F}_{2}$ e $\mathrm{F}_{3}$ para todos os informantes conforme indicam o quadro 3 e o gráfico 3. 
Quadro 3 - Valores médios de $\mathrm{F}_{1} \mathrm{~F}_{2}$ e $\mathrm{F}_{3}$ em P1 obtidos para a vogal $/ \mathrm{u} / \mathrm{e}$ suas correlatas nasal e nasalizada e respectivos valores de $\mathrm{p}$

\begin{tabular}{|c|c|c|c|c|c|}
\hline Informantes & Formantes & $/ \mathbf{u} /$ & $/ \mathbf{u N} /$ & $/ \tilde{\mathbf{u}} /$ & $\mathbf{p}$ \\
\hline \multirow{3}{*}{ IM-1 } & $\mathbf{F}_{\mathbf{1}}$ & 393 & 396 & 438 & $0.4564(\mathrm{~ns})^{(1)}$ \\
\cline { 2 - 6 } & $\mathbf{F}_{\mathbf{2}}$ & 1588 & 1640 & 1698 & 0.9743 \\
\cline { 2 - 6 } & $\mathbf{F}_{\mathbf{3}}$ & 2905 & 2887 & 2337 & 0.3984 \\
\hline \multirow{3}{*}{ IF-2 } & $\mathbf{F}_{\mathbf{1}}$ & 436 & 448 & 438 & 0.2572 \\
\cline { 2 - 6 } & $\mathbf{F}_{\mathbf{2}}$ & 1205 & 1153 & 1101 & 0.6456 \\
\cline { 2 - 6 } & $\mathbf{F}_{\mathbf{3}}$ & 2890 & 2834 & 2936 & 0.3463 \\
\hline \multirow{3}{*}{$\mathbf{I M - 3}$} & $\mathbf{F}_{\mathbf{1}}$ & 436 & 436 & 393 & 0.5735 \\
\cline { 2 - 6 } & $\mathbf{F}_{\mathbf{2}}$ & 1414 & 1463 & 1085 & 0.3855 \\
\cline { 2 - 6 } & $\mathbf{F}_{\mathbf{3}}$ & 2907 & 2993 & 2844 & 0.5309 \\
\hline
\end{tabular}

Fonte: elaboração própria

Obs.: ${ }^{(1)} \mathrm{ns}=$ não significativo para valores de $\mathrm{p}$ maiores que 0.05 .

Gráfico 3 - Valores médios em $\mathrm{Hz}$ de $\mathrm{F}_{1} \mathrm{~F}_{2}$ e $\mathrm{F}_{3}$ em P1 obtidos para a $\operatorname{vogal} / \mathrm{u} /$ e suas correlatas nasal e nasalizada

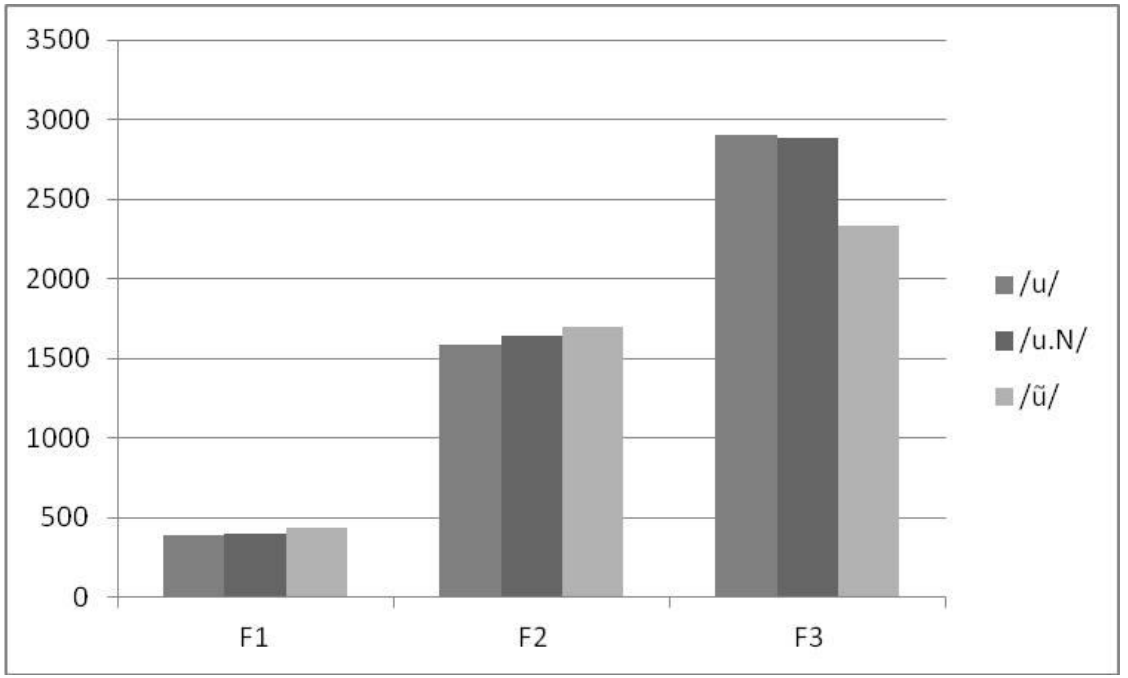

Fonte: elaboração própria 
5.2 Comparação entre os valores de $F_{1}, F_{2}$ e $F_{3}$ das vogais orais /a/, /i/ e /u/ e suas correlatas nasais e nasalizadas na posição medial

Enquanto os sons nas posições inicial e final estão mais sujeitos a interferências dos segmentos adjacentes, é na posição medial ou estacionária que o segmento atinge a configuração que o distingue dentre os demais e sofre menos os efeitos da coarticulação, por isso os investigadores da fala optam por considerar somente esse ponto do segmento na análise de questões acústicas, para evitar, assim, interpretações errôneas sobre o que se propõem a fazer e, dessa forma, estabelecer o comportamento prototípico de cada som. Por outro lado, considerar os sons nas suas posições inicial e final, exige do pesquisador um conhecimento amplo acerca dos aspectos acústico-articulatórios dos sons, de como esses aspectos se relacionam entre si e do papel que desempenham sobre os segmentos na cadeia da fala.

Assim como na porção inicial, os valores de $\mathrm{F}_{1}$ são mais altos para a vogal /a/ do que para as vogais /aN/ e /ã/, demonstrando, assim, que as vogais nasais e nasalizadas apresentam o mesmo comportamento acústico. Em relação ao $\mathrm{F}_{2}$, não houve diferença significativa para essas vogais, diferindo dos dados de Jesus (1999), que aponta para um abaixamento no valor de $\mathrm{F}_{2}$ para a vogal com a nasalização nos falantes do sexo feminino.

Quanto ao $\mathrm{F}_{3}$, esse foi realizado com valores mais baixos para a vogal /a/ na realização do IM-1 e do IM-3, sendo que, para esse falante, o valor de F3 só é menor em relação a /ã/. O quadro 4 e o gráfico 4, a seguir, ilustram tais realizações: 
Quadro 4 - Valores médios de $F_{1} F_{2}$ e $F_{3}$ em P2 obtidos para a vogal /a/ e suas correlatas nasal e nasalizada e respectivos valores de $\mathrm{p}$

\begin{tabular}{|c|c|c|c|c|c|}
\hline Informantes & Formantes & $/ \mathbf{a} /$ & $/ \mathbf{a N} /$ & $/ \tilde{\mathbf{a}} /$ & $\mathbf{p}$ \\
\hline \multirow{3}{*}{ IM-1 } & $\mathbf{F}_{\mathbf{1}}$ & $746 \mathrm{a}^{(1)}$ & $525 \mathrm{~b}^{(2)}$ & $560 \mathrm{~b}$ & $0.0001(\mathrm{~s})^{(3)}$ \\
\cline { 2 - 6 } & $\mathbf{F}_{\mathbf{2}}$ & 1337 & 1351 & 1384 & $0.3019(\mathrm{~ns})^{(4)}$ \\
\cline { 2 - 6 } & $\mathbf{F}_{\mathbf{3}}$ & $2464 \mathrm{a}$ & $2903 \mathrm{~b}$ & $2931 \mathrm{~b}$ & 0.0001 \\
\hline \multirow{3}{*}{ IF-2 } & $\mathbf{F}_{\mathbf{1}}$ & $902 \mathrm{a}$ & $767 \mathrm{~b}$ & $813 \mathrm{~b}$ & 0.0001 \\
\cline { 2 - 6 } & $\mathbf{F}_{\mathbf{2}}$ & 1623 & 1445 & 1527 & 0.0004 \\
\cline { 2 - 6 } & $\mathbf{F}_{\mathbf{3}}$ & $2443 \mathrm{a}$ & $2644 \mathrm{~b}$ & $2769 \mathrm{~b}$ & 0.0005 \\
\hline \multirow{3}{*}{$\mathbf{I M - 3}$} & $\mathbf{F}_{\mathbf{1}}$ & $728 \mathrm{a}$ & $549 \mathrm{~b}$ & $571 \mathrm{~b}$ & 0.0001 \\
\cline { 2 - 6 } & $\mathbf{F}_{\mathbf{2}}$ & 1337 & 1366 & 1304 & 0.0546 \\
\cline { 2 - 6 } & $\mathbf{F}_{\mathbf{3}}$ & $2467 \mathrm{a}$ & $2643 \mathrm{ac}$ & $2650 \mathrm{bc}$ & 0.0239 \\
\hline
\end{tabular}

Fonte: elaboração própria

Obs.: (1) Letras iguais indicam que não há diferença significativa entre as médias.

${ }^{(2)}$ Letras diferentes indicam que há diferença significativa entre as médias.

${ }^{(3)} \mathrm{s}=$ significativo para valores de $\mathrm{p}$ menores que 0.05 .

${ }^{(4)} \mathrm{ns}=$ não significativo para valores de $\mathrm{p}$ maiores que 0.05 .

Gráfico 4 - Valores médios em $\mathrm{Hz}$ de $\mathrm{F}_{1} \mathrm{~F}_{2}$ e $\mathrm{F}_{3}$ em P2 obtidos para a $\operatorname{vogal} / \mathrm{a} / \mathrm{e}$ suas correlatas nasal e nasalizada

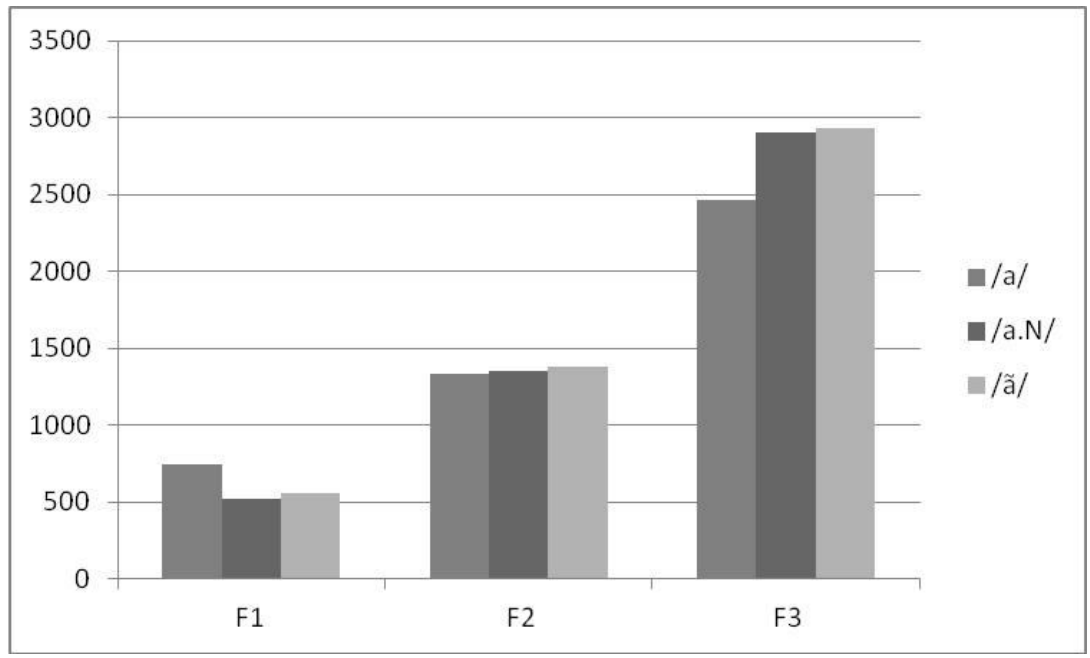

Fonte: elaboração própria 
Para as vogais /i/, /iN/, os valores de $\mathrm{F}_{1}$ são mais altos do que para /a/ nas realizações do IM-1, e não há diferença significativa nos dados do IF-2; enquanto que, para o IM-3, /1/ apresenta maior valor em relação a /i/. Quanto ao $\mathrm{F}_{2}$, observa-se diferença significativa entre os valores de /iN/ e /i/ e de /i/, sendo mais baixos para essa vogal nas realizações do IF-2; para IM-3, a diferença está só entre os valores de /iN/ e /i/, sendo que a nasal apresenta valores mais altos. Os valores de $\mathrm{F}_{3}$, por sua vez, são maiores para /i/ em relação a /i/ em IM-1; em IF-2, /iN/ e /1/ possuem valores de $\mathrm{F}_{3}$ maiores do que /i/; já para o IM-3, a diferença está entre /iN/ e /i/ com uma diferença em vantagem da nasal, de acordo com o que se apresenta no quadro 5 e no gráfico 5 a seguir:

Quadro 5 - Valores médios de $\mathrm{F}_{1} \mathrm{~F}_{2}$ e $\mathrm{F}_{3}$ em $\mathrm{P} 2$ obtidos para a vogal /i/ e suas correlatas nasal e nasalizada e respectivos valores de $\mathrm{p}$

\begin{tabular}{|c|c|c|c|c|c|}
\hline Informantes & Formantes & $/ \mathbf{i} /$ & $/ \mathbf{i N} /$ & $\mathbf{i} /$ & $\mathbf{P}$ \\
\hline \multirow{3}{*}{ IM-1 } & $\mathbf{F}_{1}$ & $309 \mathrm{a}^{(1)}$ & $370 \mathrm{~b}^{(2)}$ & $374 \mathrm{~b}$ & $0.0002(\mathrm{~s})^{(3)}$ \\
\cline { 2 - 6 } & $\mathbf{F}_{\mathbf{2}}$ & 2368 & 2131 & 2405 & $0.0671(\mathrm{~ns})^{(4)}$ \\
\cline { 2 - 6 } & $\mathbf{F}_{\mathbf{3}}$ & $3200 \mathrm{aa}$ & $3086 \mathrm{ac}$ & $3333 \mathrm{bc}$ & 0.0084 \\
\hline \multirow{3}{*}{ IF-2 } & $\mathbf{F}_{\mathbf{1}}$ & 420 & 410 & 417 & 0.1637 \\
\cline { 2 - 6 } & $\mathbf{F}_{\mathbf{2}}$ & $2606 \mathrm{a}$ & $2718 \mathrm{~b}$ & $2770 \mathrm{~b}$ & 0.0027 \\
\cline { 2 - 6 } & $\mathbf{F}_{\mathbf{3}}$ & $3025 \mathrm{a}$ & $3174 \mathrm{~b}$ & $3178 \mathrm{~b}$ & 0.0065 \\
\hline \multirow{3}{*}{$\mathbf{I M - 3}$} & $\mathbf{F}_{\mathbf{1}}$ & $276 \mathrm{a}$ & $311 \mathrm{ac}$ & $326 \mathrm{bc}$ & 0.0001 \\
\cline { 2 - 6 } & $\mathbf{F}_{\mathbf{2}}$ & $2115 \mathrm{a}$ & $2084 \mathrm{ac}$ & $2182 \mathrm{bc}$ & 0.0073 \\
\cline { 2 - 6 } & $\mathbf{F}_{3}$ & $3239 \mathrm{a}$ & $3292 \mathrm{bc}$ & $3321 \mathrm{ac}$ & 0.0007 \\
\hline
\end{tabular}

Fonte: elaboração própria

Obs.: (1) Letras iguais indicam que não há diferença significativa entre as médias. ${ }^{(2)}$ Letras diferentes indicam que há diferença significativa entre as médias. (3) $s=$ significativo para valores de $\mathrm{p}$ menores que 0.05 . ${ }^{(4)} \mathrm{ns}=$ não significativo para valores de p maiores que 0.05 . 
Gráfico 5 - Valores médios em $\mathrm{Hz}$ de $\mathrm{F}_{1,} \mathrm{~F}_{2}$ e $\mathrm{F}_{3}$ em P2 obtidos para a vogal /i/ e suas correlatas nasal e nasalizada

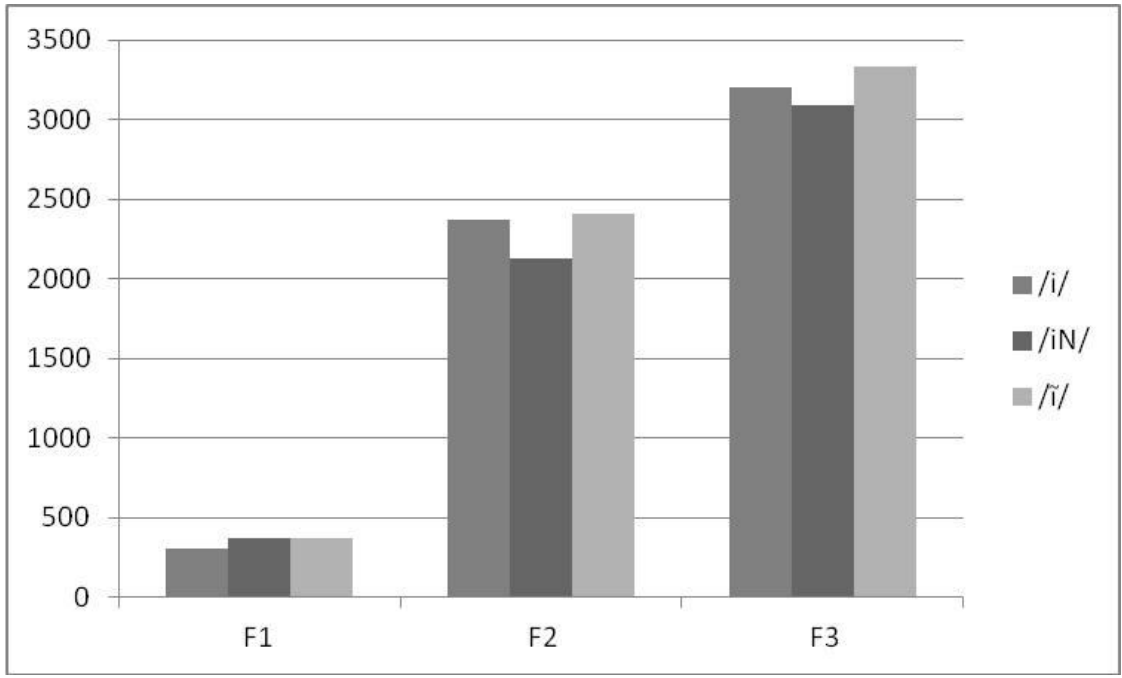

Fonte: elaboração própria

As diferenças entre os valores de $\mathrm{F}_{1}$ demonstraram-se não significativas para as vogais /u/, /uN/ e / $\tilde{u} /$ nas realizações de IM-1; para os outros informantes, o $\mathrm{F}_{1}$ de / $\tilde{\mathrm{u}} /$ é maior que o de /u/ em IF-2 e maior que o de $/ \mathrm{u} /$ e o de /uN/ em IM-3. Os valores de $\mathrm{F}_{2}$ também não apresentaram diferença significativa para /u/, /uN/ e /ũ / em IM-1, mas para IF-2, o valor de $\mathrm{F}_{2}$ de /uN/ é menor do que o de /u/ e /ũ /; em IM-3, a diferença está entre $/ \mathrm{u} / \mathrm{e} / \mathrm{uN} /$. Em relação aos valores de $\mathrm{F}_{3}$, encontra-se diferença significativa somente em IM-1 entre /u/ e /ũ /, sendo maior para a oral. Abaixo, seguem o quadro 6 e o gráfico 6 , com os dados encontrados: 
Quadro 6 - Valores médios de $\mathrm{F}_{1} \mathrm{~F}_{2}$ e $\mathrm{F}_{3}$ em P2 obtidos para a vogal $/ \mathrm{u} /$ e suas correlatas nasal e nasalizada e respectivos valores de $\mathrm{p}$

\begin{tabular}{|c|c|c|c|c|c|}
\hline Informantes & Formantes & $/ \mathbf{u} /$ & $/ \mathbf{u N} /$ & $/ \tilde{\mathbf{u}}$ & $\mathbf{p}$ \\
\hline \multirow{4}{*}{ IM-1 } & $\mathbf{F}_{\mathbf{1}}$ & 422 & 442 & 442 & $0.4776(\mathrm{~ns})^{(1)}$ \\
\cline { 2 - 6 } & $\mathbf{F}_{\mathbf{2}}$ & 2076 & 1950 & 1729 & 0.1515 \\
\cline { 2 - 6 } & $\mathbf{F}_{\mathbf{3}}$ & $3119 \mathrm{a}(2)$ & $2984 \mathrm{ac}^{(3)}$ & $2862 \mathrm{bc}$ & $0.0039(\mathrm{~s})^{(4)}$ \\
\hline \multirow{4}{*}{$\mathbf{I F - 2}$} & $\mathbf{F}_{\mathbf{1}}$ & $431 \mathrm{a}$ & $454 \mathrm{ab}$ & $494 \mathrm{~b}$ & 0.0011 \\
\cline { 2 - 6 } & $\mathbf{F}_{\mathbf{2}}$ & $1007 \mathrm{a}$ & $895 \mathrm{~b}$ & $969 \mathrm{a}$ & 0.0029 \\
\cline { 2 - 6 } & $\mathbf{F}_{\mathbf{3}}$ & $2771 \mathrm{a}$ & $2576 \mathrm{a}$ & $2794 \mathrm{a}$ & 0.0498 \\
\hline \multirow{3}{*}{$\mathbf{I M - 3}$} & $\mathbf{F}_{\mathbf{1}}$ & $384 \mathrm{a}$ & $375 \mathrm{a}$ & $499 \mathrm{~b}$ & 0.0097 \\
\cline { 2 - 6 } & $\mathbf{F}_{\mathbf{2}}$ & $1103 \mathrm{a}$ & $2268 \mathrm{~b}$ & $1643 \mathrm{ab}$ & 0.0244 \\
\cline { 2 - 6 } & $\mathbf{F}_{\mathbf{3}}$ & 2888 & 2812 & 2844 & 0.8053 \\
\hline
\end{tabular}

Fonte: elaboração própria

Obs.: ${ }^{(1)} \mathrm{ns}=$ não significativo para valores de $\mathrm{p}$ maiores que 0.05 .

(2) Letras iguais indicam que não há diferença significativa entre as médias.

${ }^{(3)}$ Letras diferentes indicam que há diferença significativa entre as médias.

${ }^{(4)} \mathrm{s}=$ significativo para valores de $\mathrm{p}$ menores que 0.05 .

Gráfico 6 - Valores médios em $\mathrm{Hz}$ de $\mathrm{F}_{1} \mathrm{~F}_{2}$ e $\mathrm{F}_{3}$ em P2 obtidos para a vogal /u/ e suas correlatas nasal e nasalizada

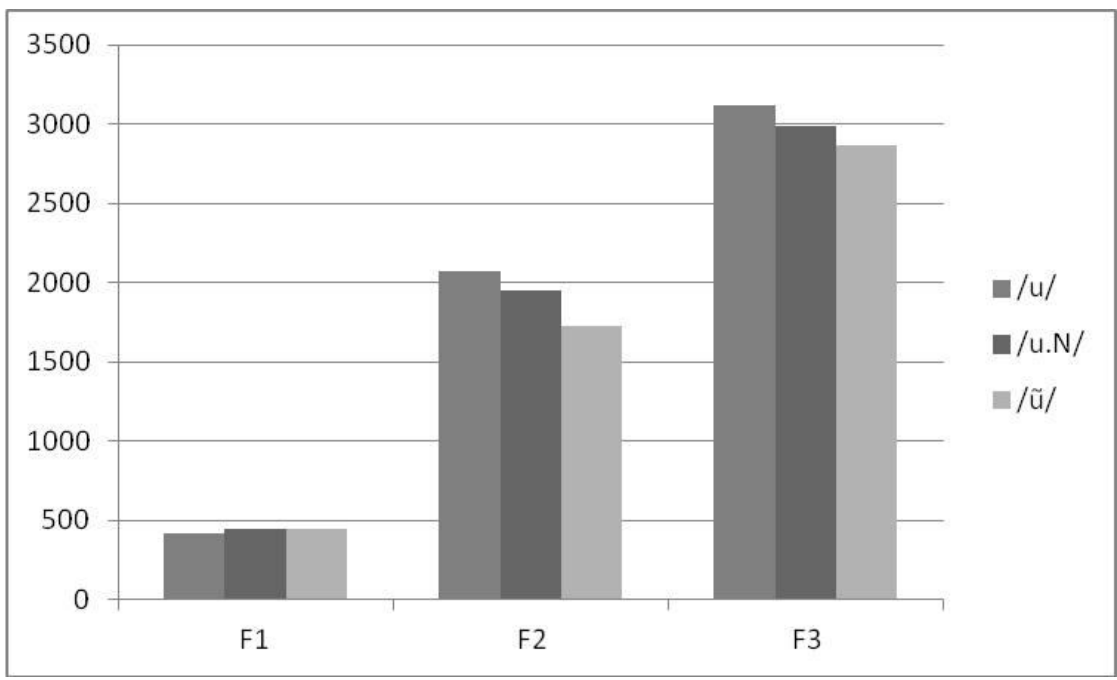

Fonte: elaboração própria

Signum: Estud. Ling., Londrina, n. 15/2, p. 401-431, dez. 2012 
5.3 Comparação entre os valores de $F_{1}, F_{2}$ e $F_{3}$ das vogais orais /a/, /i/ e /u/ e suas correlatas nasais e nasalizadas na posição final

$\mathrm{Na}$ porção final, momento em que os órgãos do aparelho fonador já se preparam para a passagem à posição adequada para a produção do próximo segmento e, por isso, as características acústicas do segmento antecedente podem ser alteradas, o valor de $\mathrm{F}_{1}$ é abaixado na vogal /aN/ em IM-1, enquanto que, em IF-2, as diferenças dos valores nas vogais /a/, / aN/ e /ã/ não são significativas; por outro lado, os valores para /a/, /aN/ e /ã / em IM-3 diferem-se significativamente entre si, sendo o valor de /a/ maior que o de /aN/ e o de / ã/ e o valor de / ã/maior que o de $/ \mathrm{aN} /$. Quanto ao $\mathrm{F}_{2}$, a diferença é encontrada somente em IM-1, para o qual o valor de /ã / é maior que o de /a/. Para o $\mathrm{F}_{3}$, apenas em IM-1, há diferença significativa: /aN/ e /ã / apresentam valores maiores que os de /a/, conforme o quadro 7 e o gráfico 7 que seguem.

Quadro 7 - Valores médios de $\mathrm{F}_{1}, \mathrm{~F}_{2}$ e $\mathrm{F}_{3}$ em $\mathrm{P} 3$ obtidos para a vogal /a/ e suas correlatas nasal e nasalizada e respectivos valores de $\mathrm{p}$

\begin{tabular}{|c|c|c|c|c|c|}
\hline Informantes & Formantes & $/ \mathbf{a} /$ & $/ \mathbf{a N} /$ & $/ \tilde{\mathbf{a}} /$ & $\mathbf{p}$ \\
\hline \multirow{3}{*}{ IM-1 } & $\mathbf{F}_{\mathbf{1}}$ & $561 \mathrm{a}^{(1)}$ & $475 \mathrm{~b}^{(2)}$ & $523 \mathrm{a}$ & $0.0039(\mathrm{~s})^{(3)}$ \\
\cline { 2 - 6 } & $\mathbf{F}_{\mathbf{2}}$ & $1357 \mathrm{a}$ & $1456 \mathrm{ac}$ & $1506 \mathrm{bc}$ & 0.0481 \\
\cline { 2 - 6 } & $\mathbf{F}_{\mathbf{3}}$ & $2502 \mathrm{a}$ & $2802 \mathrm{~b}$ & $2952 \mathrm{~b}$ & 0.0001 \\
\hline \multirow{3}{*}{ IF-2 } & $\mathbf{F}_{\mathbf{1}}$ & 704 & 664 & 693 & $0.1368(\mathrm{~ns})^{(4)}$ \\
\cline { 2 - 6 } & $\mathbf{F}_{\mathbf{2}}$ & 1648 & 1413 & 1463 & 0.0006 \\
\cline { 2 - 6 } & $\mathbf{F}_{\mathbf{3}}$ & 2528 & 2588 & 2490 & 0.5148 \\
\hline \multirow{3}{*}{$\mathbf{I M - 3}$} & $\mathbf{F}_{\mathbf{1}}$ & $644 \mathrm{a}$ & $432 \mathrm{~b}$ & $523 \mathrm{c}$ & 0.0001 \\
\cline { 2 - 6 } & $\mathbf{F}_{\mathbf{2}}$ & 1362 & 1304 & 1259 & 0.3885 \\
\cline { 2 - 6 } & $\mathbf{F}_{\mathbf{3}}$ & 2263 & 2497 & 2621 & 0.0001 \\
\hline
\end{tabular}

Fonte: elaboração própria

Obs.: (1) Letras iguais indicam que não há diferença significativa entre as médias.

(2) Letras diferentes indicam que há diferença significativa entre as médias.

${ }^{(3)} \mathrm{s}=$ significativo para valores de $\mathrm{p}$ menores que 0.05 .

${ }^{(4)} \mathrm{ns}=$ não significativo para valores de p maiores que 0.05 . 
Gráfico 7 - Valores médios em $\mathrm{Hz}$ de $\mathrm{F}_{1} \mathrm{~F}_{2}$ e $\mathrm{F}_{3}$ em P3 obtidos para a vogal / a/ e suas correlatas nasal e nasalizada

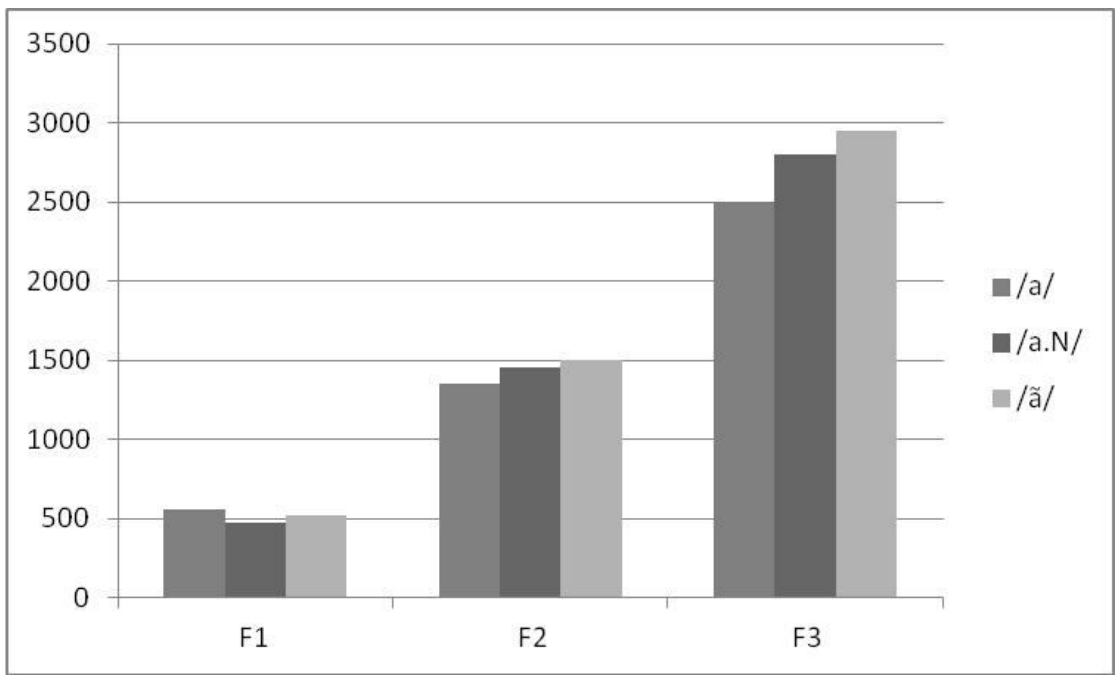

Fonte: elaboração própria

No tocante ao $\mathrm{F}_{1}$ de $/ \mathrm{i} /, / \mathrm{iN} / \mathrm{e} / \mathrm{i} /$, os valores são significativos entre /iN/ e /1/ e /i/, sendo menores para /i/ em IM-1, e entre /i/ e /i/ em IM-3, com valor maior para a nasalizada. No que diz respeito aos valores de $\mathrm{F}_{2}$, não há diferença significativa entre /i/, iN/ e $/ 1 /$ em nenhum dos informantes. Em relação ao $\mathrm{F}_{3}$, a diferença está somente em IM-3, com um valor maior para /iN/ em relação a $/ 1 /$, como mostram o quadro 8 e o gráfico 8 abaixo: 
Quadro 8 - Valores médios de $\mathrm{F}_{1} \mathrm{~F}_{2}$ e $\mathrm{F}_{3}$ em P3 obtidos para a vogal /i/ e suas correlatas nasal e nasalizada e respectivos valores de $\mathrm{p}$

\begin{tabular}{|c|c|c|c|c|c|}
\hline Informantes & Formantes & $/ \mathbf{i} /$ & $/ \mathbf{i N} /$ & $\mathbf{/} /$ & $\mathbf{p}$ \\
\hline \multirow{3}{*}{ IM-1 } & $\mathbf{F}_{\mathbf{1}}$ & $299 \mathrm{a}^{(1)}$ & $375 \mathrm{~b}^{(2)}$ & $399 \mathrm{~b}$ & $0.0001(\mathrm{~s})^{(3)}$ \\
\cline { 2 - 6 } & $\mathbf{F}_{\mathbf{2}}$ & 2303 & 2162 & 2212 & $0.9132(\mathrm{~ns})^{(4)}$ \\
\cline { 2 - 6 } & $\mathbf{F}_{\mathbf{3}}$ & 2878 & 3089 & 2997 & 0.2722 \\
\hline \multirow{3}{*}{$\mathbf{I F - 2}$} & $\mathbf{F}_{1}$ & 386 & 380 & 441 & 0.0001 \\
\cline { 2 - 6 } & $\mathbf{F}_{\mathbf{2}}$ & $2346 \mathrm{a}$ & $2457 \mathrm{ab}$ & $2276 \mathrm{ac}$ & 0.0211 \\
\cline { 2 - 6 } & $\mathbf{F}_{\mathbf{3}}$ & 3026 & 3046 & 2985 & 0.9744 \\
\hline \multirow{3}{*}{$\mathbf{I M - 3}$} & $\mathbf{F}_{\mathbf{1}}$ & $256 \mathrm{a}$ & $274 \mathrm{ac}$ & $304 \mathrm{bc}$ & 0.0312 \\
\cline { 2 - 6 } & $\mathbf{F}_{\mathbf{2}}$ & 2159 & 2122 & 2092 & 0.2552 \\
\cline { 2 - 6 } & $\mathbf{F}_{3}$ & $2948 \mathrm{a}$ & $3174 \mathrm{ab}$ & $2771 \mathrm{ac}$ & 0.0045 \\
\hline
\end{tabular}

Fonte: elaboração própria

Obs.: (1) Letras iguais indicam que não há diferença significativa entre as médias.

(2) Letras diferentes indicam que há diferença significativa entre as médias.

(3) $\mathrm{s}=$ significativo para valores de $\mathrm{p}$ menores que 0.05 .

${ }^{(4)} \mathrm{ns}=$ não significativo para valores de $\mathrm{p}$ maiores que 0.05 .

Gráfico 8 - Valores médios em $\mathrm{Hz}$ de $\mathrm{F}_{1} \mathrm{~F}_{2}$ e $\mathrm{F}_{3}$ em P3 obtidos para a vogal /i/ e suas correlatas nasal e nasalizada

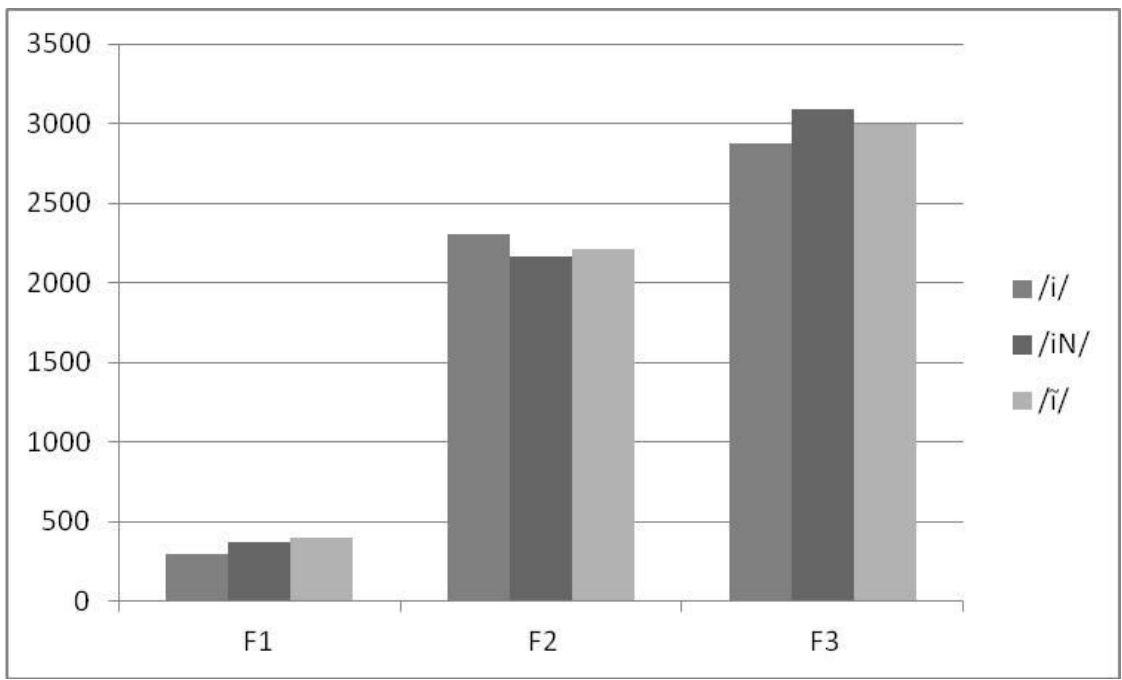

Fonte: elaboração própria 
Finalmente, entre as vogais /u/, /uN/ e / ̃̃/, em IM-1, não há diferença significativa entre os valores de $\mathrm{F}_{1}, \mathrm{~F}_{2}$ e $\mathrm{F}_{3}$ nem entre os valores de $\mathrm{F}_{2}$ e $\mathrm{F}_{3}$ em IF-2 e IM-3; diferenças significativas encontram-se somente entre os valores de $\mathrm{F}_{1}$ entre /u/ e / $\tilde{\mathrm{u}} /$ em IF-2, com valor mais alto para / $\tilde{\mathrm{u}} / \mathrm{e}$ entre /uN/ e / $\tilde{u} /$ em IM-3 com valor maior para /i/, como apontam o quadro 9 e o gráfico 9 que seguem:

Quadro 9 - Valores médios de $F_{1} F_{2}$ e $F_{3}$ em P3 obtidos para a vogal $/ \mathrm{u} /$ e suas correlatas nasal e nasalizada e respectivos valores de $\mathrm{p}$

\begin{tabular}{|c|c|c|c|c|c|}
\hline Informantes & Formantes & $/ \mathbf{u} /$ & $/ \mathbf{u N} /$ & $/ \tilde{\mathbf{u}} /$ & $\mathbf{p}$ \\
\hline \multirow{3}{*}{ IM-1 } & $\mathbf{F}_{\mathbf{1}}$ & 424 & 453 & 473 & $0.5697(\mathrm{~ns})^{(1)}$ \\
\cline { 2 - 6 } & $\mathbf{F}_{\mathbf{2}}$ & 1948 & 1864 & 1895 & 0.9616 \\
\cline { 2 - 6 } & $\mathbf{F}_{3}$ & 3151 & 3000 & 2924 & 0.2878 \\
\hline \multirow{3}{*}{$\mathbf{I F - 2}$} & $\mathbf{F}_{\mathbf{1}}$ & $361 \mathrm{a}^{(2)}$ & $398 \mathrm{ab}^{(3)}$ & $444 \mathrm{~b}$ & $0.0016(\mathrm{~s})^{(4)}$ \\
\cline { 2 - 6 } & $\mathbf{F}_{\mathbf{2}}$ & 1165 & 1001 & 1101 & 0.1494 \\
\cline { 2 - 6 } & $\mathbf{F}_{3}$ & 2773 & 2612 & 2539 & 0.0880 \\
\hline \multirow{3}{*}{$\mathbf{I M - 3}$} & $\mathbf{F}_{\mathbf{1}}$ & $423 \mathrm{a}$ & $403 \mathrm{ab}$ & $570 \mathrm{ac}$ & 0.0095 \\
\cline { 2 - 6 } & $\mathbf{F}_{\mathbf{2}}$ & 1692 & 1986 & 1866 & 0.6052 \\
\cline { 2 - 6 } & $\mathbf{F}_{3}$ & 2951 & 2872 & 2953 & 0.7328 \\
\hline
\end{tabular}

Fonte: elaboração própria

Obs.: ${ }^{(1)}$ ns= não significativo para valores de $\mathrm{p}$ menores que 0.05 .

(2) Letras iguais indicam que não há diferença significativa entre as médias.

${ }^{(3)}$ Letras diferentes indicam que há diferença significativa entre as médias.

${ }^{(4)} \mathrm{s}=$ significativo para valores de $\mathrm{p}$ menores que 0.05 . 
Gráfico 9 - Valores médios em $\mathrm{Hz}$ de $\mathrm{F}_{1} \mathrm{~F}_{2}$ e $\mathrm{F}_{3}$ em P3 obtidos para a $\operatorname{vogal} / \mathrm{u} /$ e suas correlatas nasal e nasalizada

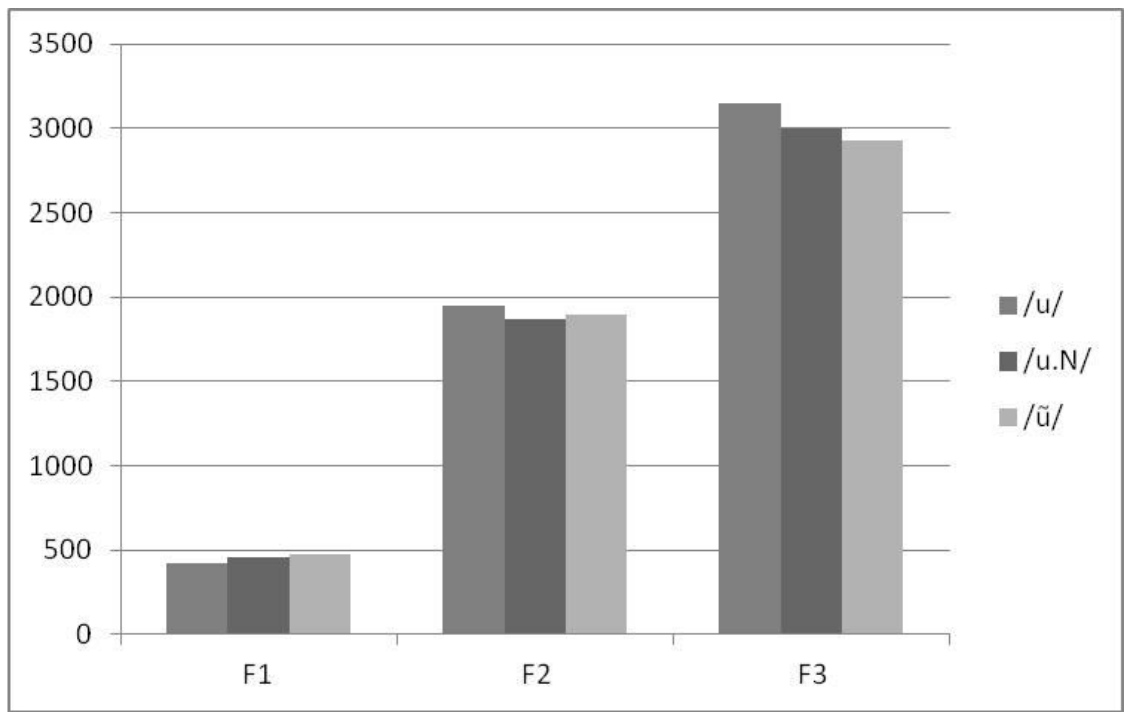

Fonte: elaboração própria

\section{Conclusões}

Em síntese, os resultados encontrados são os seguintes, para a posição inicial das vogais:

- valores de $\mathrm{F}_{1}$ de /a/ mais altos que os de /aN/ e os de /ã/; valores de $\mathrm{F}_{2}$ de /a/, /aN/ e /ã / invariáveis em IM-1; foi observada diferença entre $/ \mathrm{a} / \mathrm{e} / \mathrm{aN} / \mathrm{em}$ IF-2 e entre /a/ e /ã / em IM-3, com valores maiores para /a/ nos dois casos; valores de $\mathrm{F}_{3}$ mais altos para /a/ do que para /aN/ e /ã/ em IM-1 e em IF-2; em IM-3, a diferença é observada somente entre /a/ e /ã/, sendo maiores os valores de $\mathrm{F}_{3}$ da oral em relação aos da nasalizada;

- a diferença entre os valores de $\mathrm{F}_{1}$ de /i/, /iN/ e /1/ não é significativa; quanto ao $\mathrm{F}_{2}$, a diferença é observada somente em IM-1: o $\mathrm{F}_{2}$ de /iN/ é maior do que o de /i/; em relação ao $\mathrm{F}_{3}$, apenas em IM-3, existe diferença: o $\mathrm{F}_{3}$ de /iN/ é maior do que o de /i/; 
- entre as vogais /uN/, /u/ e /ũ/, não há diferença significativa entre as médias dos valores de $\mathrm{F}_{1}, \mathrm{~F}_{2}$ e $\mathrm{F}_{3}$.

Na posição medial, são encontrados os seguintes dados:

- valores de $\mathrm{F}_{1}$ mais altos para /a/; valores de $\mathrm{F}_{2}$ invariáveis para as vogais /a/, /aN/ e /ãa/; valores de $\mathrm{F}_{3}$ mais altos para /aN/ e / ã/; exceção para os dados do IM-3 que apresentaram diferença somente entre /ã / e /a/, com vantagem para a vogal nasalizada;

- valores de $\mathrm{F}_{1}$ mais altos para /iN/ e $/ 1 /$ em IM-1; sem diferença significativa em IF-2 e diferença em IM-3 entre $/ 1 /$ e /i/, sendo maior o valor da vogal nasalizada; valores de $\mathrm{F}_{2}$ sem diferença significativa em IM-1, mais altos para /iN/ e $/ 1 /$ em IF-2 e mais altos para $/ 1 /$ em relação a /i/ em IM-3; valores de $\mathrm{F}_{3}$ mais altos para $/ 1 /$ em relação a /i/ em IM-1, mais altos para /iN/ e $/ 1 /$ em relação a /i/ em IM-2 e mais altos somente para /iN/ em relação a /i/ em IM-3;

- quanto às vogais $/ \mathrm{u} /, / \mathrm{uN} / \mathrm{e} / \tilde{\mathrm{u}} /$, a diferença entre os seus valores de $\mathrm{F}_{1}$ não é significativa em IM-1; em IF-2, o valor de $\mathrm{F}_{1}$ de / $\tilde{\mathrm{u}} /$ é maior do que o de /u/, mas não do o que de /uN/, e, em IM-3, / ̃ / apresenta valores maiores do que / $\mathrm{uN} / \mathrm{e} / \mathrm{u} /$; a diferença entre os valores de $\mathrm{F}_{2}$ em IM-1 não é significativa; em IF-2, os valores de /uN/ são menores do que os de /u/ e os de /i/; já em IM-3, os valores de /uN/ são maiores do que os de /u/; em relação ao $\mathrm{F}_{3}$, foi observada diferença significativa somente em IM-1 entre /u/ e /ũ /, com valores maiores para a vogal oral.

Por fim, na posição final, tem-se o seguinte:

- o valor de $\mathrm{F}_{1}$ é menor na vogal /aN/ em IM-1; em IF-2, as diferenças dos valores nas vogais /a/, /aN/ e /ã / não são significativas; em IM-3, o valor de $\mathrm{F}_{1}$ de /a/ é maior que o de $/ \mathrm{aN} /$ e o de /ã/, e o valor de $\mathrm{F}_{1}$ de / $\mathrm{a} /$ é maior que o de $/ \mathrm{aN} /$; os valores $\mathrm{de}_{\mathrm{F}}$ de / ã / são maiores que os de /a/ somente em IM-1; em relação ao $\mathrm{F}_{3}$, apenas em IM-1, /aN/ e /ã / apresentam valores maiores que os de /a/.

- os valores de $\mathrm{F}_{1}$ de /iN/ e $/ 1 /$ são maiores que os de /i/ em IM-1 e, em IM-3, /1/ apresenta valores maiores que /i/; os valores de $\mathrm{F}_{2} \mathrm{de}$ /iN/ são maiores que os de $/ 1 /$ em IF-2; para os outros informantes, as diferenças não são significativas; a diferença entre os valores de $\mathrm{F}_{3}$ só é significativa em IM-3: o $\mathrm{F}_{3}$ de /iN/ é maior que o de $/ 1 /$.

- os valores de $F_{1}$ de /i/ são maiores que os de /u/ em IF-2 e maiores que os de / uN/ em IM-3; a diferença entre os valores de $\mathrm{F}_{2}$ de /u/, /uN/ e / $\tilde{u} /$ não é significativa, assim como a diferença entre os valores de $\mathrm{F}_{3}$ de $/ \mathrm{u} /, \mathrm{uN} / \mathrm{e} / \tilde{\mathrm{u}} /$. 
Pode-se afirmar, com base nesses dados, que as frequências das vogais nasais, assim como ocorre com suas contrapartidas orais, dependem da qualidade dessas vogais, ou seja, do fato de serem posteriores ou anteriores, altas ou baixas. A variação nos valores das frequências é maior, em $\mathrm{F}_{1}$, para a vogal /a/ e suas contrapartidas nasal e nasalizada nas três posições estudadas. As vogais $/ \mathrm{iN} / \mathrm{e} / \mathrm{i} /$ tendem a apresentar valores de $\mathrm{F}_{2}$ maiores que os de /i/, na posição medial. As vogais /u/, /uN/ e /ũ / sofre pouca variação nos valores de suas frequências.

As vogais / aN/ e / ã / apresentam comportamento mais delimitado em relação à sua contrapartida oral do que as outras vogais, o que, provavelmente, seja explicado pelo fato de aquelas vogais apresentarem o máximo de abertura e, por isso, possibilitarem ao véu palatino maior espaço para o seu abaixamento na nasalização. A diferença entre as nasais e as nasalizadas não é clara, em se tratando de seus formantes orais, uma vez que essas, ora se comportam como aquelas, ora como as vogais orais. É necessário, portanto, investigar outros parâmetros acústicos, como os formantes nasais e os antiformantes, por exemplo, para que se possa delimitar o padrão desses sons.

\section{Referências}

BOERSMA, P.; WEENINK, D. Praat software. Version 4.0. 15 Oct. 2001. Disponível em: <http://www.fon.hum.uva.nl/praat/>. Acesso em: 3 jul. 2012.

CAGLIARI, L. C. An experimental study of nasality with particular reference to Brazilian Portuguese. 1977. Tese (Doutorado em Linguística) - University of Edinburgh, Edinburgo. 1977.

CÂMARA JR., J. M. Estrutura da língua portuguesa. 10. ed. Petrópolis: Vozes, 1980 [1970].

CAMPOS, H. de O. V. Duração dos segmentos vocálicos orais, nasais e nasalizados do português brasileiro. 2009. Dissertação (Mestrado em Linguística) Universidade Federal de Minas Gerais, Belo Horizonte. 2009.

JESUS, M. de S. V. Estudo fonético da nasalidade vocálica em falantes normais e com fissura de palato: enfoque acústico. 1999. Dissertação (Mestrado em 
Linguística) - Universidade Federal de Minas Gerais, Belo Horizonte. 1999.

LIMA-GREGIO, A. M. et al. Achados espectrais das vogais [a] e [PD] em diferentes aberturas velofaríngeas. Pró-Fono, Barueri, v. 22, n. 4, p. 515-520, out./dez. 2010.

LOVATTO, L. et al. A fiberscopic analysis of nasal vowels in Brazilian Portuguese. In: CONGRESS OF PHONETIC SCIENCES, 16., 2007, Saarbrücken. Proceedings of the 16th International Congress of Phonetic Sciences. Saarbrücken: Saarland University, 2007. p. 549-552.

MEDEIROS, B. R. de. Vogais nasais do português brasileiro: reflexões preliminares de uma revisita. Revista Letras, Curitiba, n. 72, p. 165-188, maio/ago. 2007.

MORAES, J. A.; WETZELS, W. L. Sobre a duração dos segmentos vocálicos nasais e nasalizados em português. Um exercício de fonologia experimental. Cadernos de Estudos Lingüisticos, Campinas, n. 23, p. 153-166, jul./dez. 1992.

PACHECO, V. Micro-prosódia segmental e estrutura silábica: o caso das oclusivas - dados preliminares. Inventário, Salvador, n. 3, 2004. Disponível em: <http://www.inventario.ufba.br/03/03vpacheco.htm>. Acesso em: 3 jul. 2012.

PICKETT, J. M. The acoustics of speech communication: fundamentals, speech perception theory, and technology. United States of America: Allyn and Bacon, 1999.

SOUSA, E. M. G. de. Para a caracterização fonético-acústica da nasalidade do Português do Brasil. 1994. Dissertação (Mestrado em Linguística) Universidade de Campinas, Campinas. 1994.

SOUZA, L. C. da S.; PACHECO, V. Novas evidências fonéticoexperimentais para a natureza bifonêmica da vogal nasal do Português Brasileiro. In: SEMINÁRIO DE PESQUISA EM ESTUDOS LINGUÍSTICOS E SEMINÁRIO DE PESQUISA EM ANÁLISE DE DISCURSO, 3., 2007, Vitória da Conquista. Anais... Vitória da Conquista: Edições UESB, 2007. p. 89-93. 